Research article Open Access

\title{
Expression analysis of candidate breast tumour suppressor genes on chromosome 16q
}

\author{
Tom van Wezel ${ }^{1}$, Marcel Lombaerts ${ }^{1}$, Eddy H van Roon ${ }^{1}$, Katja Philippo ${ }^{1}$, Hans J Baelde ${ }^{1}$, \\ Karoly Szuhai ${ }^{2}$, Cees J Cornelisse ${ }^{1}$ and Anne-Marie Cleton-Jansen ${ }^{1}$
}

\author{
1Department of Pathology, Leiden University Medical Center, Albiniusdreef 2, 2333ZA Leiden, The Netherlands \\ 2Department of Human and Clinical Genetics, Leiden University Medical Center, Albiniusdreef 2, 2333ZA Leiden, The Netherlands \\ Corresponding author: Tom van Wezel, t.van_wezel@lumc.nl \\ Received: 12 Jul 2005 Revisions requested: 25 Aug 2005 Revisions received: 8 Sep 2005 Accepted: 26 Sep 2005 Published: 18 Oct 2005 \\ Breast Cancer Research 2005, 7:R998-R1004 (DOI 10.1186/bcr1337) \\ This article is online at: http://breast-cancer-research.com/content/7/6/R998 \\ (c) 2005 van Wezel et al.; licensee BioMed Central Ltd. \\ This is an Open Access article distributed under the terms of the Creative Commons Attribution License (http://creativecommons.org/licenses/by/ \\ 2.0), which permits unrestricted use, distribution, and reproduction in any medium, provided the original work is properly cited.
}

\begin{abstract}
Introduction Chromosome arm $16 \mathrm{q}$ is the second most frequent target of loss of heterozygosity in breast cancer and is, therefore, a candidate to contain one or more classic tumour suppressor genes (TSGs). E-cadherin at 16q22 was identified as a TSG in lobular breast cancer, but TSGs in ductal breast cancer remain elusive. Several genes have been suggested as potential candidates (e.g. CBFA2T3, CTCF and WWOX) but no inactivating mutations could be identified in these genes and they thus fail to fit the classic two-hit model for a TSG. With the completion of the human transcriptome, new candidate genes can be distinguished. Besides mutational inactivation, a TSG could, at least in a subset of the tumours, be transcriptionally suppressed or even inactivated. Studying candidate genes for expression and somatic mutations could thus identify the TSGs.
\end{abstract}

Methods Possible candidates CBFA2T3, TERF2 and TERF2IP, FBXL8 and LRRC29 and FANCA were studied for insertion and deletion mutations and for expression differences using quantitative RT-PCR in a panel of tumour cell lines and primary tumours with and without loss of $16 q$.

Results None of the genes showed mutations or obvious expression differences. FANCA expression increased with tumour grade.

Conclusion Apparently, the underlying genetics at chromosome $16 q$ are complex or the TSGs remain to be identified. Multiple mechanisms, such as mutations, promoter hypermethylation or haploinsufficiency, might lead to the inactivation of a TSG.

\section{Introduction}

The long arm of chromosome 16 is a frequent target for loss of heterozygosity ( $\mathrm{LOH})$ in sporadic breast cancer [1]. Detailed mapping of $\mathrm{LOH}$ revealed at least two frequently deleted genomic regions on chromosome 16q22.1 and $16 q 24.3$ that could harbour classical tumour suppressor genes (TSGs) [2,3]. Mutation analysis identified the homophilic epithelial cell adhesion gene $\mathrm{CDH} 1$ encoding $\mathrm{E}-$ cadherin, located at 16q22.1, as a TSG, but only in the histological subset of lobular breast cancer and not in the more frequent ductal breast cancer [4]. Thus, the TSGs in ductal breast cancer remain elusive. To identify these TSGs, many genes have already been screened and excluded as candidates [5-8]. Although some studies have suggested other genes as potential candidates (e.g. the transcriptional corepressor CBFA2T3 (MTG16) [9], the zinc finger transcription factor CTCF [10] or the oxidoreductase WWOX [11]), these genes fail to fit the classic two-hit model for a TSG because no inactivating mutations could be identified in the retained copy of them. Apparently the underlying genetics at chromosome $16 q$ is more complex than originally conceived or the TSGs remain to be identified [12]. Multiple mechanisms, such as mutations, promoter hypermethylation or haploinsufficiency might lead to the inactivation of a TSG [12]. Regardless of the mechanism, however, it can be expected that the TSG will, at least in a subset of the tumours, be transcriptionally suppressed or even inactivated. Thus, studying candidate genes for expression and somatic mutations could identify the TSGs.

Another problem that has hampered the identification of TSGs is the nature of the smallest region of overlap (SRO) determined by $\mathrm{LOH}$ mapping. Indeed, the selection of candidate 
Table 1

\begin{tabular}{|c|c|}
\hline & LOH $16 q$ status \\
\hline \multicolumn{2}{|c|}{ Mammary cell lines } \\
\hline BT20 & $\mathrm{LOH} 16 q 24$ \\
\hline BT474 & Retention \\
\hline BT483 & Retention \\
\hline BT549 & $\mathrm{LOH} 16 \mathrm{q}$ \\
\hline CAMA & $\mathrm{LOH} 16 \mathrm{q}$ \\
\hline Du4475 & Retention \\
\hline HBL100 & Retention \\
\hline HS578t & $\mathrm{LOH} 16 q 22$ \\
\hline MCF10A & - \\
\hline MCF10F & - \\
\hline MCF12A & - \\
\hline MCF7 & Retention \\
\hline MDA-MB-134 & $\mathrm{LOH} 16 \mathrm{q}$ \\
\hline MDA-MB-157 & LOH 16q24 \\
\hline MDA-MB-175 & Retention \\
\hline MDA-MB-231 & $\mathrm{LOH} 16 \mathrm{q}$ \\
\hline MDA-MB-330 & Retention \\
\hline MDA-MB-361 & Retention \\
\hline MDA-MB-435 & Retention \\
\hline MDA-MB-453 & LOH 16q24 \\
\hline MDA-MB-468 & $\mathrm{LOH} 16 q$ \\
\hline MPE600 & LOH $16 q$ \\
\hline OCUBF & $\mathrm{LOH} 16 q$ \\
\hline SKBR3 & $\mathrm{LOH} 16 \mathrm{q}$ \\
\hline SKBR5 & $\mathrm{LOH} 16 \mathrm{q}$ \\
\hline SUM185 & $\mathrm{LOH} 16 \mathrm{q}$ \\
\hline Sum44PE & $\mathrm{LOH} 16 \mathrm{q}$ \\
\hline SUM52 & $\mathrm{LOH} 16 \mathrm{q}$ \\
\hline T47d & $\mathrm{LOH} 16 \mathrm{q}$ \\
\hline ZR75 & $\mathrm{LOH} 16 \mathrm{q}$ \\
\hline \multicolumn{2}{|c|}{ Primary breast tissues numbers } \\
\hline 2 & Normal breast \\
\hline 11 & Retention \\
\hline 15 & $\mathrm{LOH} 16 \mathrm{q}$ \\
\hline 9 & LOH 16q21-ter \\
\hline 3 & LOH 16q22 \\
\hline 2 & $\mathrm{LOH} 16 q 24$ \\
\hline
\end{tabular}

tumour suppressor genes in previous studies is driven by the exact location of a gene in the SRO. Unfortunately, consensus on SROs is low and based on just a few tumours. The LOH events in these tumours could be based on non-specific genetic aberrations or even false-positive/negative LOH-calling. In this study, we have selected genes that are located not in the smallest region, but in the most common region, which is much larger. The selection of these candidate genes is not driven by their location but based on the function of the genes that fit that of a tumour suppressor gene or the involvement of these genes or their homologs in breast or other cancers. The study was not restricted to mutational inactivation but focussed on possible transcriptional down regulation.

With the completion of the human genome and gene maps $[13,14]$, other likely candidate genes on chromosome $16 \mathrm{q}$ have appeared. Here we describe the gene-expression analysis of new candidate genes in breast tumours.

Two interacting genes, TERF2 and TERF2IP, which are involved in telomere maintenance, reside on 16q22.1 and 16q23.1, respectively. These genes are interesting candidates because, together with several other factors, they form the TERF2 complex that is primarily involved in telomere maintenance [15]. TERF2 protects human telomeres from end-toend fusions [16] and TERF2IP has a role in the regulation of telomere length distribution [17]. Decreased expression of TERF2 was reported in leukaemia and in gastric cancer $[18,19]$, fitting a TSG function.

Two F-box proteins, FBXL8 and $L R R C 29$, are located on chromosome 16q22.1. F-box proteins determine substrate specificity of the SCF complexes in ubiquitin-proteasome proteolysis. Uncontrolled degradation of proteins may underlie the development and progression of malignancies; a deletion of the hCdc4 F-box protein was found in breast cancer [2022]. As two F-box proteins are located on 16q, these might be potential TSG candidates.

Recently, the Fanconi anaemia complex was connected to breast cancer; BRCA1 directly interacts with the Fanconi pathway, of which BRCA2 was recently identified as one component $[23,24]$. Although we previously excluded FANCA, located on 16q24, as a classic TSG by mutation analysis [5], other mechanisms could lead to inactivation of FANCA. We therefore included FANCA in the expression analysis to detect possible loss of expression in breast tumours.

We used quantitative reverse transcriptase PCR (qPCR) to perform expression studies on these genes in a panel of breast cancer cell lines and primary breast tumours with defined LOH status at chromosome $16 q[3,25,26]$. For the proper normalization of the expression levels in qPCR studies, we selected new control genes. These genes were selected from expres- 
sion data generated by microarray experiments by picking the most stably expressed genes from these experiments.

\section{Materials and methods Material and RNA isolation}

Cell lines, listed in Table 1, were obtained from ATCC, except for the MPE600 (provided by Dr F Waldman, California Pacific Medical Center), SKBr5 (provided by Dr E Stockert, SloanKettering Institute) and Sum44PE and Sum185PE (provided by Dr SP Ethier). OCUB-F was obtained from the Riken Gene Bank. All cell lines were grown in RPMI culture medium (Gibco-BRL, Grand Island,. NY, USA) with $5 \mathrm{mM}$ glutamine/ $10 \%$ fetal calf serum at $37^{\circ} \mathrm{C}$ under $5 \% \mathrm{CO}_{2}$, and harvested at $70 \%$ to $80 \%$ confluence for RNA isolation. $\mathrm{LOH}$ and physical status on chromosome 16 for these cell lines was published previously $[25,27]$.

From a series of fresh frozen breast tumours, tested for $\mathrm{LOH}$ on the long arm of chromosome 16 as described previously [3], we selected a representative panel of tumours with different $\mathrm{LOH}$ status at chromosome $16 \mathrm{q}$ and with at least $50 \%$ tumour cells on examination of a hematoxylin and eosinstained section by a pathologist. The series consists of 189 patients operated on between 1986 and 1993 in three Dutch hospitals [3]. Patient material was obtained on approval of local medical ethics committees. RNA from cell lines and snap-frozen tumours was isolated using TRIZOL (Invitrogen, Breda, The Netherlands) and subsequently purified with Qiagen RNeasy columns combined with the RNase-free DNase kit (Qiagen Sciences, Germantown, MD, USA) according to the manufacturer's instructions. cDNA was made using AMV reverse transcriptase (Roche Diagnostics, Basel, Switzerland).

\section{Quantitative reverse transcriptase PCR}

qPCR primers were designed in Primer Express (Applied Biosystems Applied Biosystems, Foster City, CA, USA) and primers for fragment analysis were designed using the primer3 program [28]. qPCR reactions were performed on an iCycler (Biorad, Hercules, CA, USA) using the SybrGreen qPCR core-kit (Eurogentec, Seraing, Belgium). Cycle conditions were: 10 minutes at $94^{\circ} \mathrm{C}$ followed by 40 cycles of $10 \mathrm{~s}$ at $94^{\circ} \mathrm{C}$ and 1 minute at $60^{\circ} \mathrm{C}$. Cycle threshold extraction was performed using the iCycler IQ software (version 3, Biorad).

The primers used were: CPSF6, 5'-AAGATTGCCTTCATGGAATTGAG-3', 5'-TCGTGATCTACTATGGTCCCTCTCT3'; CYPA, 5'-TCATCTGCACTGCCAAGACTG-3', 5'-CATGCCTTCTTTCACTTTGCC-3'; FANCA, 5'-TTAATACCTCGGTGCCCGAA-3', 5'-AGTCCCCACGATCAGCCA-3'; LRRC29, 5'-CCTGCACGCCTGCCC-3', 5'-TGCAGTCAGCTCATAGAGCAGACACTGGA-3'; HNRPM, 5'-GAGGCCATGCTCCTGGG-3', 5'TTTAGCATCTTCCATGTGAAATCG-3'; CBFA2T3, 5'ACATCTGGAGGAAGGCTGAAGAG-3', 5'-GCTCCATCTT-
Figure 1

(a)

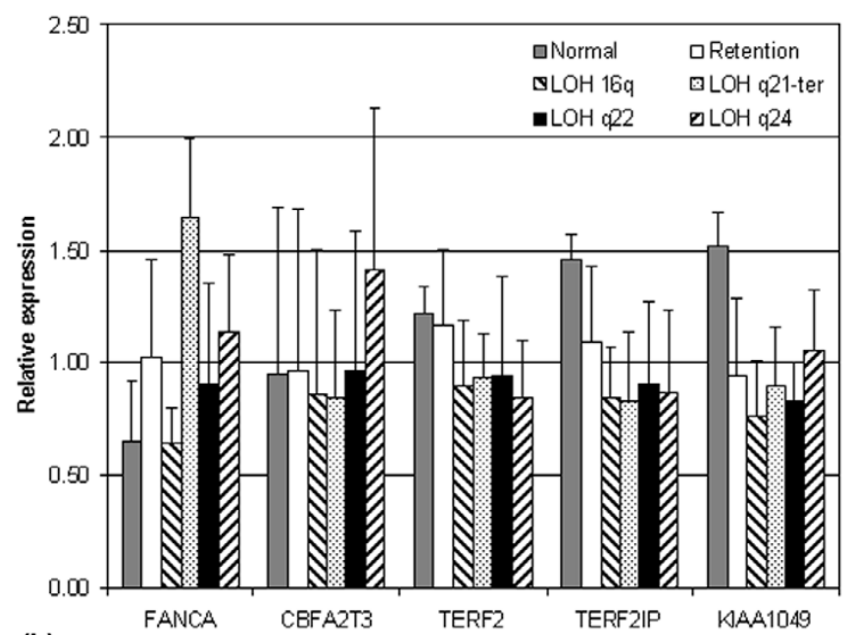

(b)

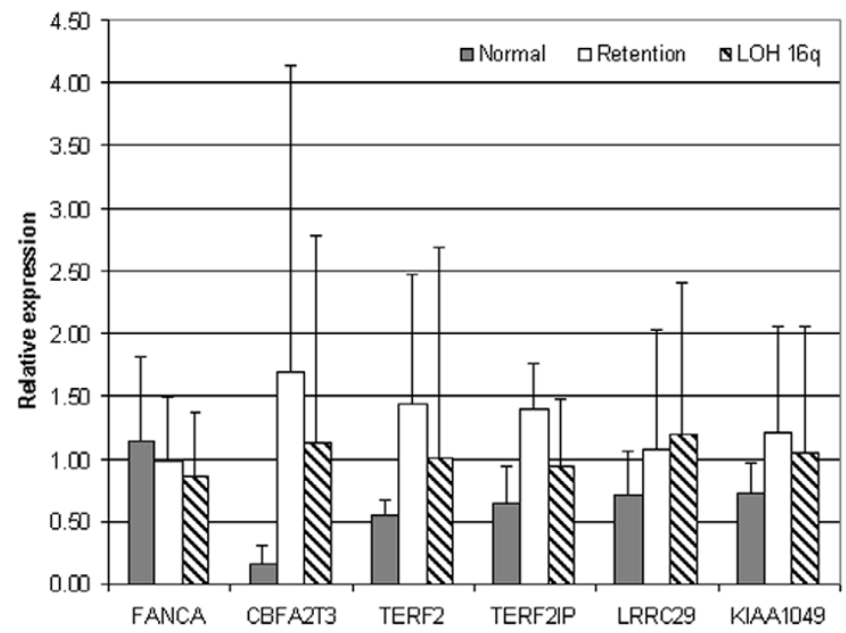

Quantitative reverse transcriptase PCR expression analysis in breast cancer cell lines and tumours. Expression analysis in (a) breast cancer cell lines and (b) breast tumours stratified according to their loss of heterozygosity $(\mathrm{LOH})$ status on the long arm of chromosome 16.

GGCACGCT-3'; PFKP, 5'-ACCCCTTCGGCATTCGAC-3', 5'-AGCAAGGCGATGACTGCC-3'; TERF2IP, 5'-AAGCTCAAGCGGAAGGCG-3', 5'-TCTGGAGTTCTCTTATTCTGTGGTTC-3'; TAF1C, 5'-GACCGCACCGGAGTGAAG-3', 5'-AACGAAAAAGCAACAGACCACA-3'; and TERF2, 5'GGTACGGGGACTTCAGACAG-3', 5'-CGCGACAGACACTGCATAAC-3'. For all PCRs, a standard curve was generated using five 1:5 dilutions of pooled cDNA from normal breast epithelial cell lines (MCF10A, MCF10F, MCF12). Relative concentrations of mRNA for each gene were calculated from the standard curve. After qPCR, dissociation curves were made to check the quality of the reaction. Reactions with more than one peak in the dissociation curve were discarded. Using the GeNorm applet, stably expressed control genes for normalization were selected; the three most stable expressed 
genes were used to calculate normalization factors for each cell line or tumour cDNA [29]. For normalization, the highest expression values for each gene were set to 1 and subsequently divided by the normalization factor generated by the GeNorm applet.

Alternatively, we calculated the rlative fold variability index (RFVI) for each gene, as described [30]. The baseline RFVls were calculated for the control genes CPSF6, HNRPM, TBP and CYPA. These ranged between 11 and 42, reflecting experimental or population variations.

\section{Fragment analysis}

Standard fragment analysis on genomic DNA was performed using fluorescent-labelled primers (Isogen Life Science, IJsselstein, The Netherlands) on an ABI377 and analysed using GeneScan and Genotyper software (Applied Biosystems). Sequencing was performed at the sequence core of the Leiden Genome Technology Center. Four genes were screened to detect small insertions and deletions. Products ranging from 200 to 500 base pairs were generated to screen the exons of TERF2IP, TERF2, LRRC29 and FBXL8 (4, 10, 4 and 6 products, respectively). Fluorescent fragment analysis detects most if not all insertions and deletions due to the size differences and detection of mutations varies from $60 \%$ to $88 \%[31,32]$.

\section{Results and discussion Quantitative reverse transcriptase PCR expression analysis}

RNA expression of the candidate TSGs at the frequently deleted long arm of chromosome 16 (FANCA, TERF2IP, TERF2, FBXL8, LRRC29 and CBFA2T3 [9]) was studied using qPCR. Expression of the genes in normal breast tissue is a prerequisite for a function as a TSG. We therefore first tested the expression by $\mathrm{QPCR}$ in three normal breast cell lines and two normal breast tissues. FANCA, TERF2IP, TERF2, $\angle R R C 29$ and CBFA2T3 were expressed in breast tissue. For $F B X L 8$, however, we failed to show any expression in normal breast, breast cell lines or breast tumours using different combinations of RT-PCR primers or northern blot analysis (not shown). We therefore excluded $F B X L 8$ from any further analysis and as a candidate TSG. Expression analysis of the genes was studied using real-time qPCR. Relative expression levels of the genes for each sample were calculated from a standard curve from the pooled normal breast cell lines, MCF10A, MCF10F and MCF12A.

\section{Control genes for normalization}

For accurate normalization of qPCR data, multiple stably expressed control genes are required [29] because expression variations in a single control gene could have significant impact on the relative expression levels of genes under study. Several control genes are widely used for normalization, such as HPRT (encoding hypoxanthine phosphoribosyl transferase
Table 2

\begin{tabular}{cll}
\hline Stability factor M for cell lines and tumours & \\
\hline Rank & Control gene & \\
\hline Cell lines & \\
1 & & \\
1 & CPSF6 & 0.58 \\
2 & CYPA & 0.58 \\
3 & TBP & 0.83 \\
4 & HNRPM & 1.08 \\
5 & $P B G D$ & 1.18 \\
6 & TAF1C & 1.27 \\
7 & $H P R T$ & 1.47 \\
8 & GAPD & 1.75 \\
Tumours & $P F K P$ & 1.96 \\
1 & & \\
1 & CPSF6 & 0.38 \\
2 & HNRPM & 0.38 \\
3 & TBP & 0.54 \\
4 & CYPA & 0.65 \\
& & 0.69 \\
\hline
\end{tabular}

1), GAPDH (encoding glyceraldehyde-3-phosphate dehydrogenase), TBP (encoding TATA box binding protein) and $P B G D$ (encoding porphobilinogen deaminase or hydroxymethylbilane synthase) [29]. The use of CYPA (encoding cyclophilin $A$ or peptidylprolyl isomerase $A$ ) has also been reported for normalization of breast cancer cell lines using qPCR [30].

For each qPCR experiment, the optimal set of controls needs to be tested and the most used controls are not necessarily the best controls. To identify additional control genes specifically suitable for breast cancer cell lines and tumours, we selected possible control genes from gene-expression microarrays hybridised with breast cancer cell lines (Lombaerts,M., van Wezel,T., Philippo,K., Dierssen,J.W.F., Zimmerman,R.M.E., Oosting,J., van Eijk,R., Eilers,P.H., Van De Water,B., Cornelisse,C.J., and Cleton-Jansen,A.M.manuscript submitted). From these cDNA arrays, the most stably expressed possible control genes with the least expression variation in multiple breast cancer cell lines were selected. These were CPSF6 (encoding cleavage and polyadenylation specific factor 6), HNRPM (encoding heterogeneous nuclear ribonucleoprotein M), PFKP (encoding the phosphofructokinase PFKP) and TAF1C (encoding TBP-associated factor, RNA polymerase IC). CPSF6, HNRPM, PFKP and TAF1C, together with HPRT, GAPDH, TBP, PBGD and CYPA, were compared for expression stability in the panel of breast cancer cell lines. Four colon tumour cell lines LS411, LS180, SW480 and 
SW837 were also included. The most stable control genes for normalization of the relative concentrations of mRNA were identified using the GeNorm software [29]. In the panel of breast cancer cell lines, the most stably expressed genes were TBP, CYPA and CPSF6 (Fig. 1), and in the colon cancer cell lines, CPSF6, HNRPM and TBP appeared the most stably expressed genes (data not shown). For the breast tumours, we tested only the genes HPRT, CYPA, TBP, CPSF6 and $H N R P M$ as the availability of tumour RNA is limited. GeNorm calculates the stability factor ' $\mathrm{M}$ ' of all control genes by comparing the variation in expression for all genes. A low M-value represents low variation in expression. Table 2 lists the stability factors for all control genes tested. CPSF6, CYPA and TBP were the most stable and were used in subsequent experiments. The commonly used control genes HPRT and GAPDH are much more variable and less suitable as control genes in breast tumours.

The identification of control genes for the normalization of qPCR experiments proved useful as both CPSF6 and HNPRM were very stably expressed in both breast cancer cell lines and tumours. In general, the control genes were more stable in the tumours than in the cell lines (for CPSF6, $M=$ 0.58 for the cell lines and $M=0.38$ in tumours). This is possibly due to multiple cell types that are present in a tumour (tumour and stromal cells and infiltrating lymphocytes) whereas cell lines usually are monocultures.

\section{Expression study in cell lines and tumours}

We used a panel of three normal breast cell lines (MCF10A, MCF10F and MCF12A), and 27 breast cancer cell lines (Table 1), 1 with LOH q22, 3 with LOH q24, 9 with retention of $16 q$ and 14 with loss of $16 q[25,27]$. Furthermore, we tested a panel of two normal breast samples and 40 breast tumours with loss of (part of) the q-arm or with retention of $16 q$ (Table 1). Expression values were normalized by a factor calculated from the three most stable control genes for the cell lines and tumours, (Table 2). Additionally, we calculated the RFVI for each gene between the samples with the highest and lowest expression, using the base-line expression value of each gene in normal breast tissue or cell line, as described previously [30]. The baseline RFVI for the control genes CPSF6, HNRPM, TBP and CYPA ranged between 11 and 42 , reflecting experimental or population variations.

As FBXL8 expression could not be detected, this gene was not included in further analysis. LRRC29 was tested first in the cell lines (Fig. 1a). This showed no difference between cell lines with and without $\mathrm{LOH}$, and also the RFVI index for $L R R C 29$ was below the baseline (Fig. 2). These data exclude $L R R C 29$ as a candidate gene and LRRC29 expression was, therefore, not studied in the tumours.

Both TERF2IP and TERF2 show somewhat reduced levels of expression in cell lines with $\mathrm{LOH}$ of chromosome arm $16 \mathrm{q}$

\section{Figure 2}

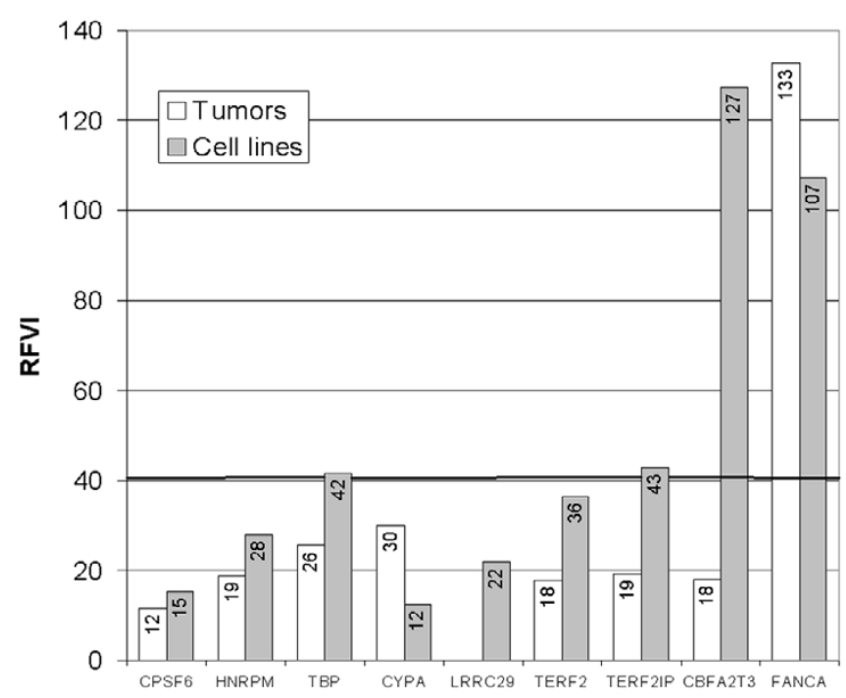

Relative fold variability index (RFVI) of the analysed candidate genes in breast tumours (hatched bars) and breast cancer cell lines (grey bars). Only FANCA and CBFA2T3 in cell lines display levels above the baseline.

\section{Figure 3}

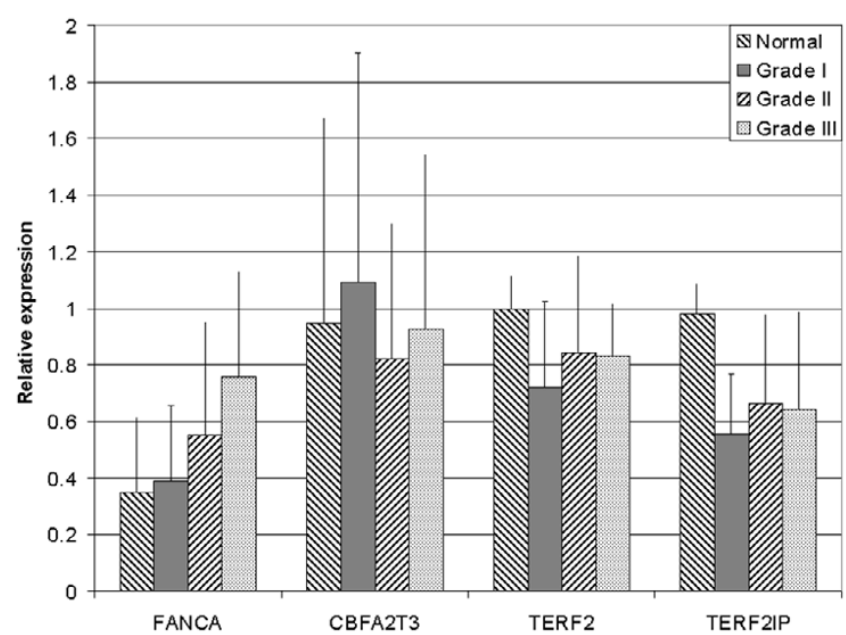

Quantitative reverse transcriptase PCR expression analysis in breast tumours according to tumour grade.

when compared with those with $16 \mathrm{q}$ retention (Fig. 1a); however, these differences are not significant. Both genes were subsequently tested in the tumour panel; again, slightly reduced expression was detected in samples with LOH (Fig 1b). However, the expression was also reduced in tumours with loss of 16q24 alone whereas TERF2IP and TERF2 are located on 16q22. The expression appears to be lower in all tumours compared to normal tissue, regardless of $\mathrm{LOH}$ or even grade (data not shown). Also, RFVI levels for TERF2IP and TERF2 are 38 and 41, respectively, which are in the same range as the housekeeping control genes (i.e. below the 
baseline level). Based on their gene expression variation, therefore, neither genes are likely to be candidate TSGs.

CBFA2T3 encodes a translocation partner of AML1 in myeloid leukaemia and a transcription repressor. Based on its location on chromosomal band 16q24.3, high variation in expression in breast cancer cell lines, loss of protein expression in breast tumours and in vitro growth inhibition of breast cancer cell lines, CBFA2T3 has been proposed as a candidate TSG $[9,30]$. We therefore tested this gene in our panel of cell lines and tumours to confirm this finding. We found a large expression variation for CBFA2T3 in cell lines, resulting in a high RFVI value of 122 (Fig. 2), which, however, was not associated with $\mathrm{LOH}$ at $16 \mathrm{q}$ (Fig. 1a). In primary tumours, there was a tendency for higher CBFA2T3 expression in tumours with LOH of $16 q 24$ (Fig. 1b), where this gene is located, and the RFVI value was below the baseline. These data do not support the candidacy of CBFA2T3 as a TSG on $16 q$.

FANCA is involved in DNA repair and located at $16 q 24.3$. Its expression in tumours is higher than in normal tissue and, remarkably, expression increases with tumour grade (Fig. 3). There is no association between $\mathrm{LOH}$ at $16 \mathrm{q}$ and tumour grade, but there is a difference in the mechanism of $\mathrm{LOH}$ when comparing low- and high-grade breast cancers. Whereas lowgrade tumours show preferential physical loss of 16q, highgrade tumours show mitotic recombination [33]. This could indicate that FANCA is involved only in well differentiated breast cancer. In cell lines, FANCA levels are slightly reduced in tumours with LOH. Interestingly, in tumours with loss of the complete q-arm, FANCA expression is lower than in those with retention of $16 \mathrm{q}$. In those with loss of q21-ter, however, expression is higher than in tumours with retention, suggesting again that the mechanism of $16 \mathrm{q} \mathrm{LOH}$ may be associated with the targeted TSG.

\section{Fragment analysis}

TERF2IP, TERF2, FBXL8 and LRRC29 were screened using fragment analysis for (small) genomic deletions or insertions in their exons in 21 breast cancer cell lines and 32 breast tumours. CBFA2T3 and FANCA were previously screened for mutations, without identifying any inactivating or somatic mutations $[5,9]$. Although TSGs are, in many cases, inactivated through deletions and insertions, no mutations were found.

\section{Conclusion}

We studied CBFA2T3, FANCA, FBXL8, LRRC29, TERF2 and TERF2IP, six potential breast cancer TSG candidate genes located on the long arm of chromosome 16, which is involved in $\mathrm{LOH}$ in more than $50 \%$ of breast cancer cases. These genes were studied using qPCR to detect possible transcriptional down-regulation in a representative panel of breast cancer cell lines and primary tumours with well defined patterns of $\mathrm{LOH}$ at chromosome 16q. For reliable qPCR, two new, stable control genes for normalization of qPCR experiments, HNRPM and CPSF6, were identified. We did not detect any significant difference in expression of the candidate genes related to the $\mathrm{LOH}$ status of tumours and cell lines. Mutation analysis of these genes did not reveal inactivating, tumour specific alterations. Therefore, these genes are unlikely to be candidates for the classic tumour suppressor gene on chromosome 16q. The identification of the underlying tumour suppressor genes and their mechanisms of inactivation remains a difficult task. New insights into neoplastic transformation indicate that somatic tumour genetics are far more complex than originally conceived, involving multiple non-classic TSGs with individual small effects [34,35]. Successful identification of these genes requires an integrated genomic approach, combining the analysis of $\mathrm{LOH}$, copy number changes and expression studies.

\section{Competing interests}

The authors declare that they have no competing interests.

\section{Authors' contributions}

TVW drafted the manuscript, performed qPCR and mutation analysis, designed and coordinated the study and performed the analysis. ML participated in study design, performed qPCR. EHVR performed $\mathrm{qPCR}$ and analysis and isolated RNA, KP performed $q P C R$ and RNA isolation HJB helped design the qPCR study, KS helped design the qPCR study, CJC participated in design, coordination of the study and AMCJ conceived of the study and participated in design, coordination of the study and helped to draft the manuscript. All authors read and approved the final manuscript.

\section{Acknowledgements}

Grant support: Dutch cancer society RUL 2000-2205. We thank Dominique Bongaerts, Anna Roukens and Sandra van Eijgen for experimental support.

\section{References}

1. Cleton-Jansen AM, Moerland EW, Kuipers-Dijkshoorn NJ, Callen DF, Sutherland GR, Hansen B, Devilee P, Cornelisse CJ: At least two different regions are involved in allelic imbalance on chromosome arm 16q in breast cancer. Genes Chromosomes Cancer 1994, 9:101-107.

2. Knudson AG Jr: Genetic predisposition to cancer. Cancer Detect Prev 1984, 7:1-8.

3. Cleton-Jansen AM, Callen DF, Seshadri R, Goldup S, Mccallum B, Crawford J, Powell JA, Settasatian C, van Beerendonk H, Moerland $\mathrm{EW}$, et al:: Loss of heterozygosity mapping at chromosome arm $16 q$ in 712 breast tumors reveals factors that influence delineation of candidate regions. Cancer Res 2001, 61:1171-1177.

4. Berx G, Cleton-Jansen AM, Nollet F, De Leeuw WJ, d van V, Cornelisse C, Van Roy F: E-cadherin is a tumour/invasion suppressor gene mutated in human lobular breast cancers. EMBO J 1995, 14:6107-6115.

5. Cleton-Jansen AM, Moerland EW, Pronk JC, van Berkel CG, Apostolou S, Crawford J, Savoia A, Auerbach AD, Mathew CG, Callen $\mathrm{DF}$, et al:: Mutation analysis of the Fanconi anaemia $\mathbf{A}$ gene in breast tumours with loss of heterozygosity at 16q24.3. $\mathrm{Br} J$ Cancer 1999, 79:1049-1052.

6. Crawford J, lanzano L, Savino M, Whitmore S, Cleton-Jansen AM, Settasatian C, d'Apolito M, Seshadri R, Pronk JC, Auerbach AD, et al.: The PISSLRE gene:structure, exon skipping, and exclusion 
as tumor suppressor in breast cancer. Genomics 1999, 56:90-97.

7. Moerland E, Breuning $\mathrm{MH}$, Cornelisse CJ, Cleton-Jansen AM: Exclusion of BBC1 and CMAR as candidate breast tumoursuppressor genes. Br J Cancer 1997, 76:1550-1553.

8. Whitmore SA, Settasatian C, Crawford J, Lower KM, Mccallum B, Seshadri R, Cornelisse CJ, Moerland EW, Cleton-Jansen AM, Tipping AJ, et al.: Characterization and screening for mutations of the growth arrest- specific 11 (GAS11) and C16orf3 genes at 16q24.3 in breast cancer. Genomics 1998, 52:325-331.

9. Kochetkova M, McKenzie OL, Bais AJ, Martin JM, Secker GA, Seshadri R, Powell JA, Hinze SJ, Gardner AE, Spendlove HE, et al.: CBFA2T3 (MTG16) is a putative breast tumor suppressor gene from the breast cancer loss of heterozygosity region at 16q24.3. Cancer Res 2002, 62:4599-4604.

10. Filippova GN, Qi CF, Ulmer JE, Moore JM, Ward MD, Hu YJ, Loukinov DI, Pugacheva EM, Klenova EM, Grundy PE, et al:: Tumorassociated zinc finger mutations in the CTCF transcription factor selectively alter tts DNA-binding specificity. Cancer Res 2002, 62:48-52.

11. Watanabe $A$, Hippo $Y$, Taniguchi $H$, Iwanari $H$, Yashiro $M$, Hirakawa K, Kodama T, Aburatani H: An opposing view on WWOX protein function as a tumor suppressor. Cancer Res 2003, 63:8629-8633.

12. Devilee P, Cleton-Jansen AM, Cornelisse CJ: Ever since Knudson. Trends Genet 2001, 17:569-573.

13. Lander ES, Linton LM, Birren B, Nusbaum C, Zody MC, Baldwin J, Devon K, Dewar K, Doyle M, FitzHugh W, et al.: Initial sequencing and analysis of the human genome. Nature 2001, 409:860-921.

14. Venter JC, Adams MD, Myers EW, Li PW, Mural RJ, Sutton GG, Smith HO, Yandell M, Evans CA, Holt RA, et al:: The sequence of the human genome. Science 2001, 291:1304-1351.

15. Ye JZ, Donigian JR, Van Overbeek M, Loayza D, Luo Y, Krutchinsky AN, Chait BT, de Lange T: TIN2 binds TRF1 and TRF2 simultaneously and stabilizes the TRF2 complex on telomeres. $J$ Biol Chem 2004, 279:47264-47271.

16. van Steensel B, Smogorzewska A, de Lange T: TRF2 protects human telomeres from end-to-end fusions. Cell 1998, 92:401-413.

17. Li B, de Lange T: Rap1 affects the length and heterogeneity of human telomeres. Mol Biol Cell 2003, 14:5060-5068.

18. Yamada K, Yagihashi A, Yamada M, Asanuma K, Moriai R, Kobayashi $D$, Tsuji N, Watanabe N: Decreased gene expression for telomeric-repeat binding factors and TIN2 in malignant hematopoietic cells. Anticancer Res 2002, 22:1315-1320.

19. Yamada M, Tsuji N, Nakamura M, Moriai R, Kobayashi D, Yagihashi A, Watanabe N: Down-regulation of TRF1, TRF2 and TIN2 genes is important to maintain telomeric DNA for gastric cancers. Anticancer Res 2002, 22:3303-3307.

20. Calhoun ES, Jones JB, Ashfaq R, Adsay V, Baker SJ, Valentine V, Hempen PM, Hilgers W, Yeo CJ, Hruban RH, et al.: BRAF and FBXW7 (CDC4, FBW7, AGO, SEL10) mutations in distinct subsets of pancreatic cancer:potential therapeutic targets. $A m \mathrm{~J}$ Pathol 2003, 163:1255-1260.

21. Mao JH, Perez-losada J, Wu D, DelRosario R, Tsunematsu R, Nakayama K, Brown K, Bryson S, Balmain A: Fbxw7/Cdc4 is a p53-dependent, haploinsufficient tumour suppressor gene. Nature 2004, 432:775-779.

22. Strohmaier $\mathrm{H}$, Spruck $\mathrm{CH}$, Kaiser $\mathrm{P}$, Won $\mathrm{KA}$, Sangfelt $\mathrm{O}$, Reed $\mathrm{SI}$ : Human F-box protein hCdc4 targets cyclin E for proteolysis and is mutated in a breast cancer cell line. Nature 2001, 413:316-322.

23. Howlett NG, Taniguchi T, Olson S, Cox B, Waisfisz $\mathrm{Q}$, DieSmulders C, Persky N, Grompe M, Joenje H, Pals G, et al:: Biallelic Inactivation of BRCA2 in Fanconi Anemia. Science 2002, 297:606-609.

24. D'Andrea $A D$, Grompe $M$ : The Fanconi anaemia/BRCA pathway. Nat Rev Cancer 2003, 3:23-34.

25. Callen DF, Crawford J, Derwas C, Cleton-Jansen AM, Cornelisse CJ, Baker E: Defining regions of loss of heterozygosity of $16 \mathrm{q}$ in breast cancer cell lines. Cancer Genet Cytogenet 2002, 133:76-82

26. Harkes IC, Elstrodt F, Dinjens WN, Molier M, Klijn JG, Berns EM, Schutte M: Allelotype of $\mathbf{2 8}$ human breast cancer cell lines and xenografts. Br J Cancer 2003, 89:2289-2292.
27. van de Wetering $M L$, Barker $N$, Harkes IC, van der Heyden $M, D i j k$ NJ, Hollestelle A, Klijn JG, Clevers H, Schutte M: Mutant E-cadherin breast cancer cells do not display constitutive Wnt signaling. Cancer Res 2001, 61:278-284.

28. Rozen S, Skaletsky H: Primer3 on the WWW for general users and for biologist programmers. Methods Mol Biol 2000, 132:365-386

29. Vandesompele J, De Preter K, Pattyn F, Poppe B, Van Roy N, De Paepe A, Speleman F: Accurate normalization of real-time quantitative RT-PCR data by geometric averaging of multiple internal control genes. Genome Biol 2002, 3:research0034.1-research0034.11.

30. Powell JA, Gardner AE, Bais AJ, Hinze SJ, Baker E, Whitmore S, Crawford J, Kochetkova M, Spendlove HE, Doggett NA, et al:: Sequencing, transcript identification, and quantitative gene expression profiling in the breast cancer loss of heterozygosity region 16q24.3 reveal three potential tumor-suppressor genes. Genomics 2002, 80:303-310.

31. Ganguly A, Rock MJ, Prockop DJ: Conformation-sensitive gel electrophoresis for rapid detection of single-base differences in double-stranded PCR products and DNA fragments:evidence for solvent-induced bends in DNA heteroduplexes. Proc Natl Acad Sci U S A 1993, 90:10325-10329.

32. Eng C, Brody LC, Wagner TM, Devilee P, Vijg J, Szabo C, Tavtigian SV, Nathanson KL, Ostrander E, Frank TS: Interpreting epidemiological research:blinded comparison of methods used to estimate the prevalence of inherited mutations in BRCA1. Med Genet 2001, 38:824-833.

33. Cleton-Jansen AM, Buerger H, Haar N, Philippo K, van de Vijver MJ, Boecker W, Smit VT, Cornelisse CJ: Different mechanisms of chromosome 16 loss of heterozygosity in well- versus poorly differentiated ductal breast cancer. Genes Chromosomes Cancer 2004, 41:109-116.

34. Fabarius A, Willer A, Yerganian G, Hehlmann R, Duesberg P: Specific aneusomies in Chinese hamster cells at different stages of neoplastic transformation, initiated by nitrosomethylurea. Proc Natl Acad Sci U S A 2002, 99:6778-6783.

35. Rubin H: Degrees and kinds of selection in spontaneous neoplastic transformation:An operational analysis. Proc Natl Acad Sci USA 2005, 102:9276-9281. 